\title{
A Patient with Juvenile Recurrent Respiratory Papillomatosis Complicated by Laryngeal Stenosis after Laryngeal Microsurgery: A Clinical Case
}

\author{
Aliya Turayeva1*, Nataliya Papulova ${ }^{1}$, Gulmira Mukhamadiyeva ${ }^{1}$, Amanzhol Baimenov $^{2}$, Rais Tulebayev ${ }^{1}$, Kseniya Shnayder $^{3}$, \\ Adil Mustafin $^{1}$ \\ ${ }^{1}$ Department of Otorhinolaryngology, NCJSC "Astana Medical University", Nur-Sultan, Kazakhstan; ${ }^{2}$ Central Hospital, Ministry \\ of Internal Affairs, Nur-Sultan, Kazakhstan; ${ }^{3}$ Department of Children's Diseases Allergology, Hematology and Endocrinology, \\ JSC "Astana Medical University", Nur-Sultan, Kazakhstan
}

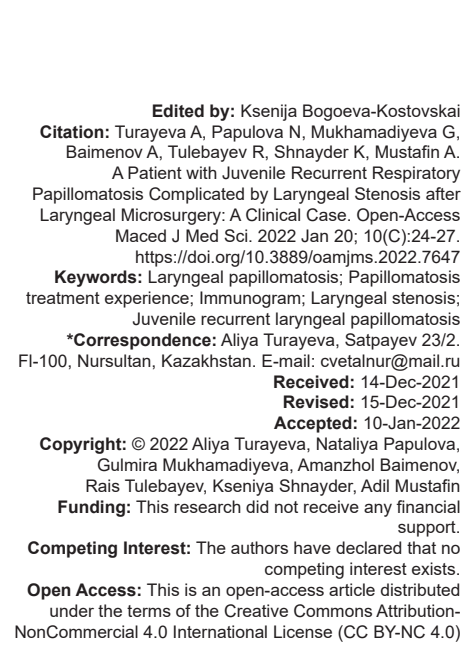

\section{Introduction}

Laryngeal papillomatosis is one of the global problems in the field of laryngology, since the exact etiopathogenesis of the disease is still not known. It is believed that about $10-60 \%$ of the world's population is infected with the human papillomavirus (HPV) latently, but not all get laryngeal papillomatosis, the causative agent of which is type 11 and 16 of this virus [1]. Juvenile respiratory laryngeal papillomatosis suggests that infection occurs secondarily, through the natural birth canal of the mother. The virus penetrates through the damaged area of the mucous membrane and affects the basal cells of the multilayered squamous epithelium [2]. Respiratory laryngeal papillomatosis is a benign neoplasm with a very low risk of dysplasia [3].

About $3.5 \%$ of neoplasms of ENT organs are laryngeal papillomatosis, which has more than 50 types of treatment [4]. The larynx and trachea are often affected by the HPV, and the oropharynx, nasopharynx, nose, and oral cavity are involved less often. HPV affects the distal airways in $48 \%$ of children. Only $3.3 \%$ of cases had lung damage. At the same time, the incidence of lung cancer among these patients was $16 \%$ [1]. It is also very rare to detect isolated papillomatosis of the trachea 
and lungs without involving the larynx [5]. Low-frequency radiation laser ablation in the treatment of laryngeal papillomatosis has shown its effectiveness in practice [6]. Removal of papillomatosis with a blue laser is basically a new method and has shown its effectiveness, since it removes tissues with minimal carbonization and minimal visible impact on surrounding tissues [7].

Along with surgical methods of treatment, conservative treatment of laryngeal papillomatosis is also used, in which there is a slow growth of the tumor. For example, treatment with cidofovir significantly lengthens the remission time of recurrent respiratory laryngeal papillomatosis [8] [9]. The study showed that HPV vaccination reduces the development of recurrent laryngeal papillomatosis [10].

\section{Study design}

Clinical case.

\section{Objective}

Surgical repair of laryngeal stenosis and achieving remission of laryngeal papillomatosis.

\section{Materials and Methods}

Patient, 5 years old, came to us in February 2016 with the complaints of persistent hoarseness, asthma attacks, and dyspnea for 4-5 months. The child was hyposthenic, covered with cold sweat. Breathing was rapid, with a characteristic stenotic noise when breathing. During inhalation, there was a retraction of intercostal spaces, jugular, and supraclavicular pits. Cyanosis of the lips, mucous membranes, and skin were observed. Examination with fiber-optic laryngoscope showed a widespread growth of laryngeal papillomas complicated by stenosis of Grades 3-4 (Figure 1).

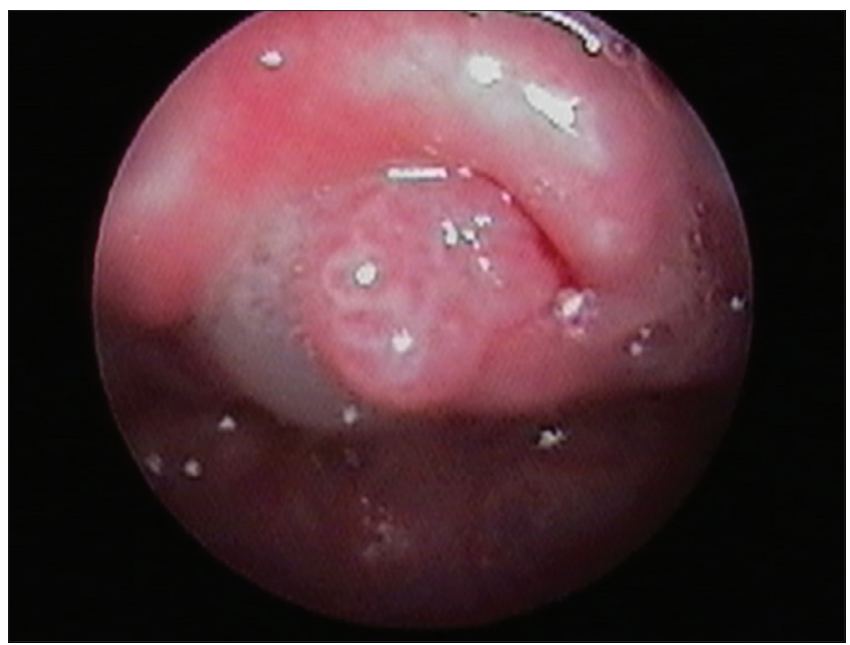

Figure 1: Endolaryngoscopic picture of the larynx before surgery

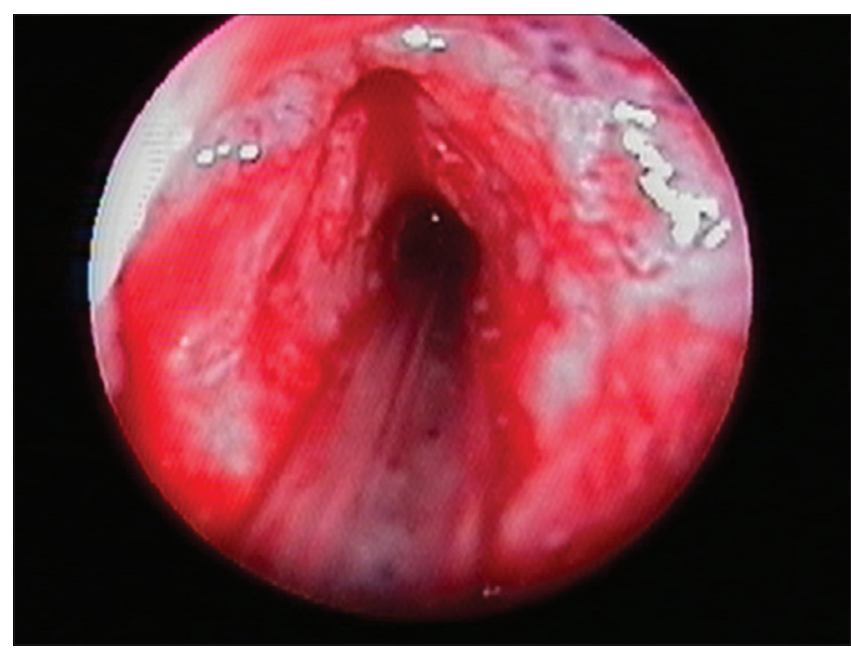

Figure 2: Endolaryngoscopic picture after surgery

The patient was hospitalized, emergency tracheostomy and endolaryngeal papilloma removal surgery were performed.

The patient contacted us again after 10 months. It turned out from the anamnesis that during this period of time, the child was subjected to endolaryngeal microsurgical repairs 6 times: With cold instruments and a $\mathrm{CO}_{2}$ laser at intervals of 1.5-2 months due to recurrent papillomatosis (Figure 2) and decannulated after two surgical treatments. Diagnosis: Laryngeal papillomatosis, common form, recurrent course with 3-4 grade stenosis.

Taking into account the widespread growth of papillomas in the larynx, frequent relapse, the patient was recommended to consult an immunologist-allergist (December 2016). An immunologist was examined and the results of the tests showed the following:

\begin{tabular}{ll}
\hline Analysis from December 29, 2016 & \\
\hline Total IgE & $44.45 \mathrm{MU} / \mathrm{ml}$ \\
CLIA HPV IgM & 0.27 \\
CMV IgG & 26.53 \\
HBsAg & $2.0 \mathrm{MU} / \mathrm{ml}$ \\
ELISA-HPV IgM & Not detected \\
\hline HPV: Human papillomavirus & \\
& \\
\hline Skin allergic testing from December 29, 2016 & +++ \\
\hline Pillow feather & ++ \\
House dust mite & ++ \\
Sheep wool & ++ \\
Whole chicken egg & +++ \\
Aspergillus & ++ \\
Test control & + \\
\hline
\end{tabular}

Based on the anamnesis and the results of the tests, the immunologist-allergist diagnosed: Primary immunodeficiency, unspecified (deficiency in the production of specific antibodies); allergic rhinitis, persistent form, moderate course, and stage of incomplete remission. Basic medical treatment was prescribed: (1) Lycopene $1 \mathrm{mg}$ for 10 days under the tongue in between meals. Repeat the course in a month. (2) Inhalation of B2 fast-acting agonists (Berodual solution) through a nebulizer 12 drops. (3) Montelukast sodium $5 \mathrm{mg} 1$ tablet at night for 1 month, then a repeat course after 15 days. (4) Xyzal/Zyrtec 1 capsule $x$ 2 times a day from the $1^{\text {st }}$ days of ARVI for $7-10$ days. 
(5) Acyclovir $200 \mathrm{mg} 1$ tablet 4 times a day, after eating for 6 days (Aciclostad) (compliance with a fat-free diet, due to hepatotoxicity, nephrotoxicity of the drug). (6) Viferon 500.000 units during the 2 months.

Recommendations were also given on the observance of hypoallergenic life: Hygiene of the nose and eyes, wearing sunglasses, masks from April to September, to exclude contact with dust, feather, wool, dampness, chemicals (chlorine and chlorine-containing products), hygiene of the home, daily peak flow monitoring, and hypoallergenic diet. The patient underwent two courses of treatment with an allergist-immunologist in 2017.

The treatment made it possible to achieve remission within 3 months. Previously, relapses occurred monthly and surgical repair was required. Subsequently, the patient underwent endolaryngeal surgery once for laryngeal papillomatosis with minimal overgrowth. Also patient was undergoing endolayngeal surgery on vocal cord twice due to a postoperative complication-cicatricial stenosis of the larynx (membranous vocal folds) from 2017 to 2018, where a remission of laryngeal papillomatosis was established. Further follow-up of the patient with a phoniatrist and an immunologist-allergist is recommended.

The control fibrolaryngoscopy of the patient was performed in September 2021 (Figure 3). As shown in Figure 3, there is a post-operative scar and a slight deformation of the left vocal cord. At present, no recurrence of respiratory laryngeal papillomatosis has been detected. The patient's voice was sonorous and without hoarseness.

In 2017, a second examination was carried out by an allergist-immunologist and repeated tests were

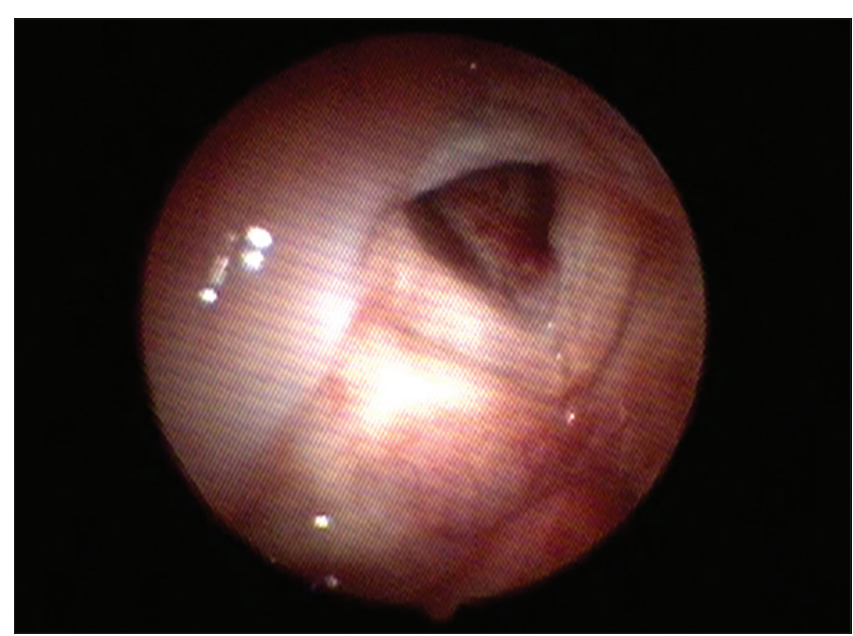

Figure 3: Endovideolaryngoscopy of the larynx

prescribed to assess the immune status. According to the analysis results: Total IgE - $30.45 \mathrm{MU} / \mathrm{ml}$; HPV $\lg$ - 9.93; and CMV IgG - 20.53; there is a decrease in indicators, which indicates the effectiveness of the treatment. According to clinical indicators, there is a significant improvement, which is indicated by the absence of relapses. Further observation by an otolaryngologist, an allergist-immunologist, and repeated courses of treatment, if necessary, is recommended.

\section{Conclusion}

The study in 2021 showed that the patient is in remission. Children with prolonged hoarseness must undergo laryngoscopy. Furthermore, this clinical case shows the importance of studying the immune status of patients with laryngeal papillomatosis, which allows us to identify changes in cellular and humoral connections of the immune status - a decrease in all populations of T-lymphocytes and quantitative deficiency of $\mathrm{B}$ cells, a decrease in the main classes of immunoglobulins. These results make it reasonable to use immunomodulatory therapy in these patients. Treatment of laryngeal papillomatosis should be comprehensive and in addition to surgical treatment should include differential immune correction.

\section{Ethics Statement}

This clinical case was part of the clinical observation by the staff of our department.

\section{Authors' Contributions}

All authors declare that there are no conflicts of interest regarding the present study.

\section{References}

1. Seedat RY. Juvenile-onset recurrent respiratory papillomatosis diagnosis and management-a developing country review. Pediatric Health Med Ther. 2020;11:39-46. https://doi. org/10.2147/PHMT.S200186

PMid:32099513

2. Kurita T, Chitose SI, Sato K, Sakazaki T, Fukahori M, Sueyoshi S, et al. Pathological mechanisms of laryngeal papillomatosis based on laryngeal epithelial characteristics. Laryngoscope Investig Otolaryngol. 2019;4(1):89-94. https://doi.org/10.1002/ lio2.242

PMid:30828624

3. Karatayli-Ozgursoy S, Bishop JA, Hillel A, Akst L, Best SR. Risk factors for dysplasia in recurrent respiratory papillomatosis in an adult and pediatric population. Ann 
Otol Rhinol Laryngol. 2016;125(3):235-41. https://doi. org/10.1177/0003489415608196

PMid:26453486

4. Svistushkin VM, Starostina SV, Egorov VI, Ragimov AA, Mustafaev DM, Matveev AV et. al. The analysis of the effectiveness of the combined treatment of patients with laryngeal papillomatosis. Vestn Otorinolaringol. 2017;82(1):4751.https:// doi: 10.17116/otorino201782147-51

PMid: 28252590

5. Cuestas G, Rodríguez V, Doormann F, Munzón PB, Munzón GB. Tracheobronchial and pulmonary papillomatosis without involvement of the larynx treated with intravenous Bevacizumab in a child. Arch Argent Pediatr. 2019;117(1):e72-e76. https://doi. org/10.5546/aap.2019.e72

PMid:30652461

6. Hao F, Yue L, Yin X, Wang X, Shan C. Low-temperature radiofrequency coblation reduces treatment interval and post-operative pain of laryngotracheal recurrent respiratory papillomatosis. Biosci Rep. 2020;40(5):BSR20192005. https:// doi.org/10.1042/BSR20192005

PMid:32426815
7. Ulmschneider C, Baker J, Vize I, Jiang J. Phonosurgery: A review of current methodologies. World $\mathrm{J}$ Otorhinolaryngol Head Neck Surg. 2020;7(4):344-53. https://doi.org/10.1016/j. wjorl.2020.09.001

PMid:34632350

8. Gazia F, Galletti B, Freni F, Bruno R, Sireci F, Galletti C, et al. Use of intralesional cidofovir in the recurrent respiratory papillomatosis: A review of the literature. Eur Rev Med Pharmacol Sci. 2020;24(2):956-962. https://doi.org/10.26355/ eurrev_202001_20081

PMid:32017003

9. Mitra S, Das A, Ghosh D, Sengupta A. Postoperative systemic acyclovir in juvenile-onset recurrent respiratory papillomatosis: The outcome. Ear Nose Throat J. 2019;98(1):28-31. https://doi. org $/ 10.1177 / 0145561318823311$

PMid:30834790

10. Milner TD, Harrison A, Montgomery J, MacGregor FB, Buchanan MA, MacKenzie K. A retrospective case-control analysis of the efficacy of Gardasil[ vaccination in 28 patients with recurrent respiratory papillomatosis of the larynx. Clin Otolaryngol. 2018;43(3):962-965. https://doi.org/10.1111/coa.13076

PMid:29380936 